\begin{tabular}{|l|l|l|}
\hline \multicolumn{2}{|c|}{ PublisherInfo } \\
\hline \hline PublisherName & $:$ & BioMed Central \\
\hline \hline PublisherLocation & $:$ & London \\
\hline \hline PublisherImprintName & $:$ & BioMed Central \\
\hline \hline
\end{tabular}

\title{
Late steroid therapy in primary acute lung injury
}

\begin{tabular}{|l|l|l||}
\hline \multicolumn{2}{|c|}{ ArticleInfo } \\
\hline \hline ArticleID & $:$ & 1653 \\
\hline \hline ArticleDOI & $:$ & $10.1186 /$ rr-2001-68587 \\
\hline \hline ArticleCitationID & $:$ & 68587 \\
\hline \hline ArticleSequenceNumber & $:$ & 64 \\
\hline \hline ArticleCategory & $:$ & Paper Report \\
\hline \hline ArticleFirstPage & $:$ & 1 \\
\hline \hline ArticleLastPage & $:$ & 3 \\
\hline \hline & & RegistrationDate $:$ 2001-9-20 \\
& $:$ & Received \\
\hline ArticleHistory & Accepted 2000-6-29 & $:$ 2001-9-20 \\
& $:$ & OnlineDate $\quad: 2001-9-20$ \\
\hline \hline ArticleCopyright & $:$ & Biomed Central Ltd2001 \\
\hline \hline ArticleGrants & $:$ & 129312211 \\
\hline \hline ArticleContext &
\end{tabular}


Ognjen Gajic, Aff1

Corresponding Affiliation: Aff1

\begin{tabular}{|l|l|}
\hline Linear View & Structure View \\
\hline
\end{tabular}

Aff1 Mayo Clinic, Rochester, MN, USA

\section{Keywords}

ALI, ARDS, corticosteroids, fibroproliferation, methylprednisolone, pneumococcal pneumonia

\section{Introduction}

Pharmacologic treatments of patients with ARDS have so far produced disappointing results. The use of steroids early in the course of the disease has been shown, in randomized trials, to be ineffective and potentially harmful. The recently introduced idea of selective steroid use, in patients with unresolving ARDS and a protracted fibroproliferative phase, has shown some promise.

\section{Comments}

This retrospective study adds some evidence to support the use of high dose steroid treatment in acute respiratory distress syndrome (ARDS). No explanation of how patients were selected for the treatment group was given. The study included only patients with primary (pulmonary) ARDS the majority of whom had pneumococcal pneumonia. This stratification of patients represents a comparatively novel approach in the evaluation of the various treatment strategies. The increased risk of infection associated with steroid treatment is a major concern. The finding of no increase in nosocomial infection, despite meticulous and invasive screening, is reassuring. As late phase steroid administration is the only treatment for which there is any evidence of benefit and now further evidence of a lack of detrimental effects, it should be considered for all unresolving ARDS patients. Until the results of a large scale randomized trial (such as the one currently being conducted by the ARDS network, ARDSnet) are available more specific recommendations cannot be made.

\section{Methods}


31 consecutive patients from one intensive care unit (ICU) with primary (pulmonary) ARDS on mechanical ventilation for $>10$ days

Exclusions: Patients with prior steroid treatment, chronic immunosuppression, neuromuscular disease or surgery during the first 10 days of ICU study

16 patients received late steroid therapy, the remaining 15 served as a control group.

Retrospective study with contemporary controls

Variables assessed: demographics, etiology of respiratory failure, blood and (BAL) cultures, APACHE II scores, multiorgan failure (MODS) scores, $\mathrm{PaO}_{2} / \mathrm{FiO}_{2}$ ratio, C-reactive protein (CRP) levels, nosocomial infection levels, duration of mechanical ventilation, ICU and hospital length of stay and 30 day mortality rate

\section{Results}

The treatment and control groups were well matched for age, gender, APACHE II scores, $\mathrm{PaO}_{2} / \mathrm{FiO}_{2}$ ratio and etiology of ARDS. Pneumococcal pneumonia was the most common etiology (11 patients in the steroid group and seven in the control) followed by community acquired pneumonia and gastric content aspiration. Ventilator management and supportive care were similar in both groups. There was no significant difference in mortality, nosocomial infection levels, length of stay and duration of mechanical ventilation between the two groups. $\mathrm{PaO}_{2} / \mathrm{FiO}_{2}$ ratios improved within the first 3 days of steroid treatment and were associated with a fall in CRP levels. In a subgroup of patients with pneumococcal pneumonia steroid administration was also associated with significant decrease in MODS $(-2.3$ vs $0.6 P=0.002)$ and a trend towards reduced 30 day mortality $(18.2 \%$ vs $42.8 \%)$

\section{Additional information}

\section{References}

1. Varpula T, Pettilä V, Rintala E, Takkunen O, Valtonen V: Late steroid therapy in primary acute lung injury. Intensive Care Med. 2000, 26: 526-531.

This PDF file was created after publication. 